\title{
Treatment of obstruction of the superior vena cava by combination chemotherapy with and without irradiation in small-cell carcinoma of the bronchus
}

\author{
SG SPIRO, S SHAH, PG HARPER, JS TOBIAS, DM GEDDES, RL SOUHAMI \\ From University College Hospital, the London Chest Hospital, and Brompton Hospital, London
}

\begin{abstract}
In a randomised prospective trial of chemotherapy with and without radiotherapy in small-cell carcinoma of the bronchus, 37 of 366 patients presented with obstruction of the superior vena cava at the time of diagnosis. In the study all patients received four cycles of combination chemotherapy over a period of 12 weeks and, provided there was not progressive disease, then received either radiotherapy to the mediastinum and primary tumour followed by eight further courses of chemotherapy or eight cycles of chemotherapy alone. Of the 37 patients presenting with superior vena caval obstruction, nine had relapsed and treatment was stopped during or after the initial four cycles of chemotherapy. Of the remainder, 15 patients received radiotherapy plus chemotherapy and 13 chemotherapy alone. After four cycles of chemotherapy (12 weeks) 21 of the 37 patients had initial complete relief of symptoms secondary to superior vena caval obstruction, 10 had substantial but partial relief, and six had no relief. Twelve patients developed recurrence of superior vena caval obstruction, of whom six had received radiotherapy and four chemotherapy alone; two relapsed in the initial 12 weeks of the study. The median survival of the patients with superior vena caval obstruction allocated at diagnosis to either treatment arm was identical. The survival of patients with obstruction was similar to that of other patients in the main study. Chemotherapy is an effective treatment for superior vena caval obstruction and there appears to be no additional advantage in giving radiotherapy after 12 weeks of cyclical chemotherapy.
\end{abstract}

Patients with carcinoma of the bronchus who present with obstruction of the superior vena cava are generally considered to require urgent treatment by irradiation for rapid relief of symptoms..$^{1-3}$ The commonest histological cell type to be associated with superior vena caval obstruction is small-cell carcinoma, in which such obstruction occurs in about $10 \%$ of cases. Small-cell carcinoma of the bronchus is usually disseminated at presentation and the conventional treatment is cytotoxic chemotherapy. Nevertheless, superior vena caval obstruction in small-cell carcinoma has for long been considered specifically to call for immediate radiotherapy with or without subsequent chemotherapy. ${ }^{13}$ It has been a criterion for exclu-

Address for reprint requests: Dr SG Spiro, Brompton Hospital, London SW3 6HP.

Accepted 14 March 1983 sion from the recent Medical Research Council study of chemotherapy and radiotherapy in limited small-cell carcinoma of the bronchus. ${ }^{4}$ Although recent small studies have shown chemotherapy to be effective in promptly relieving the distressing symptoms of superior vena caval obstruction ${ }^{5-7}$ there is no information about the survival of patients presenting with obstruction who are treated with chemotherapy alone. The importance of radiotherapy given in addition to cyclical combination chemotherapy for long-term control of superior vena caval obstruction is not known. We have examined this question as part of a randomised study evaluating the effect of irradiation in patients with small-cell carcinoma of the bronchus receiving cyclical chemotherapy.

\section{Patients and methods}

Of 366 consecutive untreated patients with small- 
cell carcinoma of the bronchus who had been entered into a randomised study of cyclical combination chemotherapy alone versus the same chemotherapy schedule with the addition of radiotherapy to the mediastinum, 37 patients had superior vena caval obstruction at presentation. All patients were randomised at diagnosis to receive one of two treatments. In both arms of the study patients received the same initial four courses of chemotherapy, each course given at three-weekly intervals. They were then reassessed after 12 weeks (three weeks after the start of the fourth course) and all those who did not have progressive disease received either a further eight courses of chemotherapy or radiotherapy and then eight courses of chemotherapy, according to randomisation. Radiotherapy was directed to the primary tumour site as assessed at 12 weeks and to the mediastinum. The supraclavicular fossa was included if metastatic lymphadenopathy had been present at the time of the original diagnosis.. The total dose of radiotherapy was $40 \mathrm{~Gy}$ (4000 rads) given in 20 daily fractions over four weeks with supervoltage equipment and anteroposterior opposed fields. Chemotherapy was recommended three weeks after completion of radiotherapy. The chemotherapy comprised alternating courses of adriamycin $50 \mathrm{mg} / \mathrm{m}^{2}$ with vincristine $2.0 \mathrm{mg}$; and cyclophosphamide $1.0 \mathrm{~g} / \mathrm{m}^{2}$ with methotrexate 50 $\mathrm{mg} / \mathrm{m}^{2}$ every three weeks. Thus each patient received six courses of each pair of drugs if the total treatment was completed. Full doses of each drug were given if the total white cell count was over $3 \cdot 0$ $\times 10^{9} / 1$ and platelet count over $100 \times 10^{\%} / 1$. The adriamycin, cyclophosphamide, and methotrexate doses were reduced by half if the white cell count was $2 \cdot 5-3.0 \times 10^{9} / 1$ or the platelet count $75-100$ $\times 10^{9} / 1$. If the white cell count was under 2.5 or the platelet count under $75 \times 10^{9} / 1$ the treatment was postponed until the counts had recovered. Patients who had progressive disease at 12 weeks or at any later stage in the study were withdrawn from treatment and received only analgesics, corticosteroids, or palliative radiotherapy for specific symptoms when indicated.

Initial staging investigations included posteroanterior and lateral chest $x$-ray examination, fibreoptic bronchoscopy with biopsy and brushings, full blood count, determination of urea and electrolyte concentrations, liver function tests, bone marrow aspiration, and bone scanning. A liver scan was performed if the liver was clinically enlarged or liver function tests were abnormal. The restaging at 12 weeks consisted of chest radiography, biochemical tests, and fibreoptic bronchoscopy with biopsy and brushings.
Results

All 37 patients had obvious clinical signs of superior vena caval obstruction at presentation with mediastinal abnormality apparent on the chest radiograph. Their mean age was 62 years and there were 19 men and 18 women. Eight had limited disease at presentation, confined to one lung, the mediastinum, and ipsilateral supraclavicular fossa; and 29 had extensive disease. Sixteen patients received chemotherapy alone and 18 the combined treatment of chemotherapy plus radiotherapy. Three patients died within the first two weeks of their first course of treatment from disseminated disease and had not been randomly allocated to a treatment group at the time of their death but are included in the results.

When response was assessed after four courses of chemotherapy there were two complete responders with normal radiographic and bronchoscopic appearances and no evidence of extrathoracic disease, and 14 partial responders with at least $50 \%$ or greater reduction in tumour mass in two perpendicular diameters on the chest radiograph. Twenty-one patients had a less than $50 \%$ radiographic response or had evidence of disease progression, or had died. Of the 21 non-responders nine had progressive disease by 12 weeks.

Of the 28 patients continuing in the study after the initial 12 weeks, 15 received radiotherapy as planned but in only three was the general disease controlled sufficiently well to complete the planned 12 courses of chemotherapy. Thirteen patients received chemotherapy alone after 12 weeks and six completed all 12 courses with good disease control (table 1).

The response of superior vena caval obstruction during treatment in the two arms of the study is summarised in table 1. Although response was assessed and reported at 12 weeks the patients are divided into three groups according to whether the disease progressed before 12 weeks, between 12 weeks and the end of the treatment period, or after that time. Of the 37 patients, 21 achieved complete symptomatic relief of symptoms of superior vena caval obstruction. Another 10 had substantial but incomplete relief (a $50 \%$ or greater reduction of symptoms using a simple scale) and six none at all. Twelve patients developed a recurrence of obstruction, of whom four were considered too ill to justify palliative radiotherapy because of disseminated disease; the other eight received palliative radiotherapy. There were six relapses with superior vena caval obstruction in patients who received radiotherapy to the mediastinum between 12 and 16 weeks and four in the group receiving chemotherapy alone. 
Table 1 Clinical response of symptoms of superior vena caval obstruction at 12 weeks in the 37 patients

\begin{tabular}{|c|c|c|c|c|c|}
\hline & \multirow[t]{2}{*}{$\begin{array}{l}\text { Disease progressed before } \\
12 \mathrm{w}\end{array}$} & \multicolumn{2}{|c|}{$\begin{array}{l}\text { Disease progressed between } \\
\text { 5th and } 12 \text { th courses* }\end{array}$} & \multicolumn{2}{|c|}{ Treatment completed } \\
\hline & & CT & $\mathrm{CT}+\mathrm{RT}$ & CT & $\mathrm{CT}+\mathrm{RT}$ \\
\hline $\begin{array}{l}\text { No of patients in group } \\
\text { Complete symptomatic response } \\
\text { Partial symptomatic response } \\
\text { No response }\end{array}$ & $\begin{array}{l}9 \\
2 \\
2 \\
5\end{array}$ & $\begin{array}{l}7 \\
4 \\
3\end{array}$ & $\begin{array}{r}12 \\
6 \\
5 \\
1\end{array}$ & $\begin{array}{l}6 \\
6\end{array}$ & $\begin{array}{l}3 \\
3\end{array}$ \\
\hline $\begin{array}{l}\text { Palliative } R T \text { at relapse } \\
\text { Relapse, no palliative } R T\end{array}$ & 2 & 2 & $\begin{array}{l}2 \\
3\end{array}$ & $\begin{array}{l}1 \\
1\end{array}$ & 1 \\
\hline
\end{tabular}

*Four patients still having treatment in remission.

SVCO-superior vena caval obstruction; CT-chemotherapy; RT-radiotherapy.

The pattern of relapse in the 37 patients is summarised in table 2 . Twelve patients relapsed with disease at the primary site and recurrent superior vena caval obstruction. Interestingly, the addition of a radiation dose of $40 \mathrm{~Gy}$ to the mediastinum did not increase protection from local recurrence as six of the 10 relapses after 12 weeks' treatment occurred in patients who had completed mediastinal irradiation. Another five patients had relapse at the primary site but did not develop superior vena caval obstruction again. In most patients the site of initial relapse was extrathoracic, the brain being the commonest site with 14 cases of cerebral metastases (diagnosed by computed tomography). Seven patients are still alive, one in complete remission.

The median survival of the patients presenting with superior vena caval obstruction is summarised in table 3, and is compared with results for the whole study. The overall survival of 283 days is similar to that for the 329 patients presenting with small-cell carcinoma of the bronchus and no superior vena caval obstruction. There were only eight patients with limited disease and a statistically valid median survival was not available.

In those who responded to treatment the mean interval before relapse was 149 days for the group

Table 2 Site of relapse in patients presenting with superior vena caval obstruction related to time of disease progression and treatment

\begin{tabular}{|c|c|c|c|c|c|}
\hline & \multirow[t]{2}{*}{$\begin{array}{l}\text { Disease progressed before } \\
12 \mathrm{w}\end{array}$} & \multicolumn{2}{|c|}{$\begin{array}{l}\text { Disease progressed between } \\
\text { 5th and } 12 \text { th courses }\end{array}$} & \multicolumn{2}{|c|}{ Treatment completed } \\
\hline & & CT & $\mathrm{CT}+\mathrm{RT}$ & CT & $\mathbf{C T}+\mathbf{R T}$ \\
\hline $\begin{array}{l}\text { No of patients in group (total } \\
\text { relapsed }=30 \text { ) } \\
\text { Site of relapse* }\end{array}$ & 9 & 5 & 10 & 3 & 3 \\
\hline $\begin{array}{l}\text { Site of relapse* } \\
\text { Primary site with SVCO } \\
\text { Primary site, no SVCO } \\
\text { Extrathoracic }\end{array}$ & $\begin{array}{l}2 \\
1 \\
3\end{array}$ & $\begin{array}{l}2 \\
2 \\
4\end{array}$ & $\begin{array}{r}5 \\
1 \\
14\end{array}$ & $\begin{array}{l}2 \\
1 \\
4\end{array}$ & $\frac{1}{3}$ \\
\hline
\end{tabular}

* More than one site in some patients.

Abbreviations as in table 1.

Table 3 Median survival (days) of patients presenting with superior vena caval obstruction compared with that of all other patients according to disease extent at presentation and treatment

\begin{tabular}{|c|c|c|c|c|c|}
\hline & \multicolumn{2}{|c|}{ SVCO group } & \multicolumn{3}{|c|}{ Whole group studied* } \\
\hline & $\begin{array}{l}\text { No of } \\
\text { patients }\end{array}$ & Median survival & $\begin{array}{l}\text { No of } \\
\text { patients }\end{array}$ & Median survival & $p$ \\
\hline $\begin{array}{l}\text { Total group } \\
\text { With extensive disease } \\
\text { With limited disease }\end{array}$ & $\begin{array}{r}37 \\
29 \\
8\end{array}$ & $\begin{array}{l}283 \\
276 \\
7-432 \\
\text { (range) }\end{array}$ & $\begin{array}{l}329 \\
209 \\
120\end{array}$ & $\begin{array}{l}249 \\
192 \\
326\end{array}$ & $\begin{array}{l}0.5 \\
0.9\end{array}$ \\
\hline $\begin{array}{l}\text { Treatment by randomisation } \\
\text { Treatment by chemotherapy alone } \\
\text { Treatment by CT }+ \text { RT }\end{array}$ & $\begin{array}{l}16 \\
18\end{array}$ & 288 & $\begin{array}{l}177 \\
152\end{array}$ & $\begin{array}{l}253 \\
249\end{array}$ & $\begin{array}{l}0.9 \\
0.9\end{array}$ \\
\hline $\begin{array}{l}\text { Extensive disease } \\
\text { CT alone } \\
\text { CT + RT }\end{array}$ & $\begin{array}{l}15 \\
12\end{array}$ & $\begin{array}{l}304 \\
242\end{array}$ & $\begin{array}{l}108 \\
101\end{array}$ & $\begin{array}{l}166 \\
224\end{array}$ & $\begin{array}{l}0.5 \\
0.6\end{array}$ \\
\hline
\end{tabular}

*Excluding the patients with superior vena caval obstruction.

Abbreviations as in table 1. 
receiving chemotherapy alone and 195 days for the chemotherapy plus radiotherapy group - the initial 84 days ( 12 weeks) of treatment being similar. The precise time of relapse was not always easy to assess. Relapse was not always associated with recurrence of superior vena caval obstruction and occurred most frequently in extrathoracic sites (table 2). Of the 12 patients whose relapse did include recurrence of obstruction, the median survival from relapse in the eight who received palliative radiotherapy was 68 days, and only 24 days in the four patients too ill for further treatment.

\section{Discussion}

It has already been shown, in series smaller than the current study, that combination chemotherapy is frequently effective for resolving symptoms of superior vena caval obstruction in small-cell carcinoma of the bronchus. Seven patients with obstruction responded well to lomustine, cyclophosphamide, and methotrexate ${ }^{5}$ and 22 of 26 patients responded to one of two cytotoxic regimens. ${ }^{6}$ In the study of Kane $e t a l^{5}$ only four patients received chemotherapy alone and the numbers are too small to draw conclusions. There was a single recurrence in this group having chemotherapy alone and one recurrence among the three patients who received additional radiotherapy. In the study of Dombernowsky and Hansen ${ }^{6}$ patients with limited disease received radiotherapy to the tumour and mediastinum and half of these patients had additional radiotherapy to the abdomen and brain. Twentyone of 26 patients achieved remission of superior vena caval obstruction but we cannot establish precisely who did and who did not receive mediastinal radiotherapy. Four of 15 patients $(27 \%)$ who also received radiotherapy relapsed with superior vena caval obstruction. Of 11 patients with extensive disease treated with chemotherapy alone, four relapsed with obstruction but subsequently responded to radiotherapy. The median survival for all 26 patients was 228 days.

In our 37 patients with superior vena caval obstruction a complete symptomatic response was obtained in 21 cases by 12 weeks, which is somewhat less than in the studies quoted above. These criteria are subjective, however, and bear little relation to quantifiable reduction of tumour bulk. Even though 21 patients had complete symptomatic relief only two achieved a complete remission as judged by our criteria, while 14 had a partial response and five a lesser response.

This study provides the first randomised comparison between chemotherapy and chemotherapy plus radiotherapy in patients presenting with superior vena caval obstruction. As the control of disease at the primary site is often inadequate in small-cell carcinoma of the bronchus with chemotherapy alone it was logical to assume that additional local treatment with radiotherapy should be beneficial. Radiotherapy had no such effect, however, with slightly more relapses with obstruction in the combination treatment group than in the group having chemotherapy alone. Relapse at an extrathoracic site was the commonest cause of death. Thus death was due to failure of chemotherapy to prevent disease dissemination, and this remains as important a problem in patients presenting with superior vena caval obstruction as in those who present with other manifestations of small-cell carcinoma of the bronchus. The median survival in our patients with obstruction was similar to that in the main study and somewhat longer than that found by Dombernowsky and Hansen. ${ }^{6}$

The initial treatment with chemotherapy failed to control the disease in nine of 37 patients $(25 \%)$ at 12 weeks and 16 patients (42\%) achieved a complete or partial remission. Since the overall response rate for the whole study was $46 \%$, the patients with superior vena caval obstruction treated with chemotherapy fared no worse than most patients in the trial, and the rate of early progressive disease was less than for the overall study.

The high rate of response to chemotherapy in this study and others ${ }^{56}$ justifies this as initial treatment in small-cell carcinoma of the bronchus. In such an aggressive disease early deaths, particularly among patients with extensive disease, are unavoidable. Few deaths, however, were clearly attributable to superior vena caval obstruction alone, which confirms the conclusion of Schraufnagel et al, ${ }^{8}$ who in reviewing 107 cases of superior vena caval obstruction from all causes found no support for the claim that such obstruction is in itself a radiotherapeutic emergency. In 19 cases of smallcell carcinoma of the bronchus treated with radiotherapy the median survival was 4.7 months, identical to that for lung cancer of the other cell types they reported, and considerably less than in the patients reported here.

Death in small-cell carcinoma of the bronchus remains a consequence of failure of chemotherapy to control disease dissemination. Rapid control of superior vena caval obstruction can be achieved with chemotherapy as with most presenting symptoms in small-cell carcinoma of the bronchus. The addition of radiotherapy after three months of chemotherapy has neither given further protection against relapse at the primary site nor improved overall survival. Superior vena caval obstruction should not be 
treated differently from other presentations of small-cell carcinoma of the bronchus.

We are grateful to the Cancer Research Campaign for support, and to Miss A Betchley for her careful typing.

\section{References}

' Roswit B, Kpalan G, Jacobson HG. The superior vena cava obstruction syndrome in bronchogenic carcinoma. Radiology 1953;61:722-36.

${ }^{2}$ Mittal BB. Treatment of the SVC syndrome. N Engl J Med 1980;301:61.
${ }^{3}$ Rubin P, Green J, Holzwasser G, Gerle R. Superior vena cava syndrome. Radiology 1963;81:388-401.

4 MRC Lung Cancer Working Party. Study of cytotoxic chemotherapy and radiotherapy in the treatment of small-cell carcinoma: third small-cell study. Thorax 1982;37:778

${ }^{5}$ Kane RC, Cohen MH, Broder LE, Bull MI. Superior vena caval obstruction due to small-cell anaplastic lung carcinoma. JAMA 1976;235:1717-18.

'Dombernowsky P, Hansen HH. Combination chemotherapy in the management of superior vena caval obstruction in small-cell anaplastic carcinoma of the lung. Acta Med Scand 1978204:513-6.

${ }^{7}$ Greco FA, Oldham RK. Small-cell lung cancer. $N$ Engl J Med 1979;301:355-7.

${ }^{8}$ Schraufnagel DE, Hill R, Leech JA, Paré JAP. Superior vena caval obstruction: is it a medical emergency? Am J Med 1981;70:1169-74. 